Erratum doi: https://doi.org/10.1007/s00376-020-2007-1

\title{
Erratum to: Estimate of Hydrofluorocarbon Emissions for 2012-16 in the Yangtze River Delta, China
}

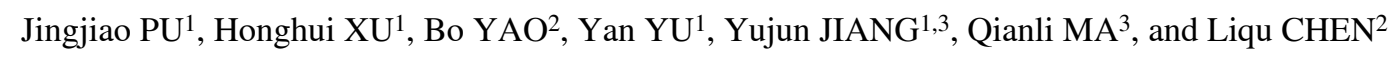 \\ ${ }^{1}$ Zhejiang Meteorological Science Institute, Hangzhou 310008, China \\ ${ }^{2}$ Meteorological Observation Center of China Meteorological Administration, Beijing 100081, China \\ ${ }^{3}$ Zhejiang Lin'an Atmospheric Background National Observation and Research Station, Hangzhou 311307, China
}

ESM to : Pu, J. J., H. H. Xu, B. Yao, Y. Yu, Y. J. Jiang, Q. L. Ma, and L. Q. Chen, 2020: Estimate of hydrofluorocarbon emissions for 2012-16 in the Yangtze River Delta, China. Adv. Atmos. Sci., 37(6), 576-585, https://doi.org/10.1007/ s00376-020-9242-3.

In the original version of this article, the unit of the YRD total HFC emissions " $\mathrm{Gg} \mathrm{CO}_{2}-\mathrm{e} \mathrm{yr}^{-1}$ " in the abstract should be $\mathrm{Tg} \mathrm{CO}_{2}$-e $\mathrm{yr}^{-1}$.

On Page 581, in the fifth line from the left bottom, the unit of the total $\mathrm{CO}_{2}$-equivalent emissions of $\mathrm{HFCs}$ " $\mathrm{Gg} \mathrm{yr}^{-1}$ " should be $\mathrm{Tg}_{\mathrm{yr}}{ }^{-1}$.

The online version of this original article can be found at https://doi.org/10.1007/s00376-020-9242-3 